\title{
DESEMPENHO SISTEMA DE IRRIGAÇÃO FIXA EM MICROASPERSOR DE ALTA VAZÃO PARA CONDIÇÕES DO NORTE DO ESTADO DO ESPÍRITO SANTO
}

\author{
Jean Karlos Barros Galote ${ }^{1}$ \\ Robson Bonomo²
}

Resumo: Advento das mudanças climáticas, a escassez hídrica torna-se fator de risco para agricultura, responsável pela retirada de $70 \%$ da água doce dos mananciais. A fim de minimizar os desperdícios, buscam-se sistemas de irrigação eficientes bem manejados. Uma forma de verifica a eficiência de um sistema de irrigação é por meio da avaliação da uniformidade de aplicação de água. O coeficiente de uniformidade de Christiansen (CUC) é uma ferramenta eficiente e bastante utilizada. A fim de avaliar o desempenho de um sistema de irrigação fixa em microaspersor de alta vazão, para as condições climáticas do norte do Espírito Santo, avaliou-se o CUC para o sistema de irrigação operando sobre as pressões de serviço de 155, 207, 258 e $310 \mathrm{kPa}$, em diferentes horários (04h00min, 12h00min, e 21h00min) no período de setembro de 2015 a julho de 2016, compreendendo a estações secas e chuvosas. O CUC variou de 77,4 a 93,5\% em virtude do horário e pressão utilizada.

Palavras-chave Manejo; Eficiência, Uniformidade.

\footnotetext{
1 Mestre em Agricultura Tropical/Universidade Federal do Espírito Santo, Brasil, E-mail: jeankarlos10@hotamil.com.

2 Prof. D.Sc. em Engenharia Agrícola /Universidade Federal do Espírito Santo, Brasil, E-mail: robson.bonomo@gmail.com.
} 